\title{
Infecção oculta pelo vírus da hepatite B em comunidade amazônica submetida a intenso fluxo migratório, estado do Pará, Brasil
}

\section{Occult hepatitis B virus infection in an Amazonian community submitted to intense migratory flow, Pará State, Brazil}

Heloisa Marceliano Nunes', Manoel do Carmo Pereira Soares', Vânia Pinto Sarmento', Andreza Pinheiro Malheiros ', Márcio Roberto Teixeira Nunes ${ }^{2}$

I Instituto Evandro Chagas/SVS/MS, Seção de Hepatologia, Belém, Pará, Brasil

${ }^{2}$ Instituto Evandro Chagas/SVS/MS, Centro de Inovações Tecnológicas, Ananindeva, Pará, Brasil

\begin{abstract}
RESUMO
INTRODUÇÃO: A infecção oculta pelo vírus da hepatite B - VHB (IOB) é definida como a presença do VHB-DNA no fígado, que pode ou não ser detectada no soro com HBsAg-, e suas possíveis implicações clínicas. OBJETIVO: Investigar a ocorrência de $\mathrm{IOB}$ na população do município de Juruti, estado do Pará, Brasil, entre fevereiro de 2007 e novembro de 2010. MATERIAIS E MÉTODOS: Foram avaliadas, por técnicas imunoenzimáticas, amostras de soro de 3.991 indivíduos, e selecionadas as anti-HBc total+ isolado, nas quais foi investigado o VHB-DNA para identificar a presença de IOB. RESULTADOS: $O$ estudo encontrou $0,5 \%$ de portadores, $8,3 \%$ com perfil de infecção pregressa, 1,1\% com perfil de infecção pregressa ou atual e 33,6\% com resposta vacinal, caracterizando - Município como de baixa endemicidade para esse vírus. O VHB-DNA foi detectado em $66,7 \%$ das amostras $\mathrm{HBsAg}+$, com carga viral entre $<55 \mathrm{UI} / \mathrm{mL}$ e $>38.000 \mathrm{UI} / \mathrm{mL} ; 69,2 \%$ dessas amostras apresentaram subgenótipo $\mathrm{Al} ; 15,4 \%, \mathrm{~F} 2$; e $15,4 \%, \mathrm{~F} 4$. Do total examinado, 1,1\% eram amostras de indivíduos anti-HBc total+ isolado, cujos testes de biologia molecular revelaram que 9,3\% apresentavam VHB-DNA, com carga viral entre < $15 \mathrm{UI} /$ $\mathrm{mL}$ e $48 \mathrm{UI} / \mathrm{mL}$. CONCLUSÃO: Os achados do estudo indicaram a presença de portadores de $1 \mathrm{OB}$ em $0,1 \%$ da população de Juruti. A baixa prevalência de $\mathrm{IOB}$ encontrada provavelmente está relacionada à baixa endemicidade do VHB nessa população.
\end{abstract}

Palavras-chave: Vírus da Hepatite B; Hepatite Viral Humana; Técnicas de Genotipagem.

\begin{abstract}
INTRODUCTION: Occult hepatitis B virus (HBV) infection (OBI) is defined as the presence of HBV DNA in liver, which may or not be detected in the serum with $\mathrm{HBsAg}_{-}$, and its possible clinical implications. OBJECTIVE: To investigate the $\mathrm{OBI}$ occurrence in the population of the municipality of Juruti, Pará State, Brazil, from February 2007 to November 2010. MATERIALS AND METHODS: Serum samples of 3,991 individuals were evaluated by immunoenzymatic techniques. The ones anti-HBc total+ isolated were selected, and from these the HBV DNA was investigated to identify OBI presence. RESULTS: In relation to HBV, the study showed $0.5 \%$ of carriers, $8.3 \%$ with a previous infection profile, $1.1 \%$ with a previous or current infection profile, and $33.6 \%$ with a vaccine response, characterizing that municipality as low endemicity for this virus. HBV DNA was detected in $66.7 \%$ of the $\mathrm{HBsAg}+$ samples, with viral load between $<55 \mathrm{IU} / \mathrm{mL}$ and $>38,000 \mathrm{IU} / \mathrm{mL} ; 69.2 \%$ of these samples were $A 1$ subgenotype, $15.4 \% \mathrm{~F} 2$, and $15.4 \% \mathrm{~F} 4$. Of the total, $1.1 \%$ were samples from individuals anti-HBc total+ isolated whose molecular biology tests showed that $9.3 \%$ had HBV DNA, with viral load between $<15 \mathrm{IU} / \mathrm{mL}$ and $48 \mathrm{IU} / \mathrm{mL}$. CONCLUSION: The findings of this study indicated the presence of $\mathrm{OBI}$ carriers in $0.1 \%$ of the Juruti population. The low prevalence of OBI found is probably related to the low endemicity of HBV in this population.
\end{abstract}

Keywords: Hepatitis B virus; Human Viral Hepatitis; Genotyping Techniques.

\footnotetext{
Correspondência / Correspondence:

Heloisa Marceliano Nunes

Instituto Evandro Chagas, Seção de Hepatologia

Av. Almirante Barroso, 492. Bairro: Marco - CEP: 66093-020 - Belém, Pará, Brasil - Tel.: +55 (91) $3214-2131$

E-mail: heloisanunes@iec.pa.gov.br
} 


\section{INTRODUÇÃO}

A hepatite $B$ somente foi reconhecida há cerca de 130 anos, com os primeiros registros realizados durante uma investigação de casos de icterícia pós-vacinação antivariólica em trabalhadores do estaleiro de Bremen, na Alemanha'. O vírus da hepatite B (VHB) pertence à família Hepadnaviridae, gênero Orthohepadnavirus, espécie Hepatitis $B$ virus².

A infecção oculta pelo vírus da hepatite B (IOB) foi descrita no final da década de 1970, revelando a importância da presença do anti-HBc como indicador de infecção pelo VHB e levantando a hipótese de que indivíduos com títulos elevados de anti-HBc poderiam transmitir a infecção ${ }^{3}$.

O diagnóstico da $\mathrm{IOB}$ é eminentemente sorológico e virológico, observando-se, de forma constante, - baixo nível do VHB-DNA, geralmente em torno de $10^{3}$ cópias $/ \mathrm{mL}$ no soro, quando comparado ao nível de $10^{4}$ cópias $/ \mathrm{mL}$ encontrado nos portadores assintomáticos e de $10^{8}$ cópias $/ \mathrm{mL}$ nos portadores de hepatite crônica ${ }^{4,5}$.

Em um workshop internacional sobre IOB realizado em Taormina, na Itália, especialistas fizeram recomendações, entre as quais se destacou a definição de IOB como a presença do VHB-DNA no fígado (com ou sem a detecção do VHB-DNA no soro) de indivíduos $\mathrm{HBsAg}$ - por testes convencionais ${ }^{6}$.

Permanecem controversos os resultados de vários estudos sobre a relação entre a $\mathrm{IOB}$ e o retardo no clareamento do $\mathrm{HBsAg}$; enquanto alguns estudos demonstram um impacto benéfico do clareamento do $\mathrm{HBsAg}$, outros sugerem elevada incidência na progressão da doença e no desenvolvimento de complicações $7,8,9,10,11$.

A resposta imune do hospedeiro para a infecção pelo VHB pode ser anulada por imunossupressores ou por agentes citotóxicos, proporcionando replicação viral e progressão da doença. A reativação da hepatite crônica $B$ ou mesmo o surgimento de falência hepática fulminante foi relatada em pacientes com $\mathrm{IOB}$ submetidos à terapia citotóxica, a transplante autólogo de células-tronco, transplante alogênico de medula óssea, linfoma, anemia aplástica ou

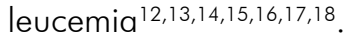

A associação entre $\circ \mathrm{VHB}$ e $\mathrm{O}$ carcinoma hepatocelular ( $\mathrm{CHC}$ ) está bem estabelecida, entretanto, permanece controverso se a IOB também estaria implicada no surgimento do $\mathrm{CHC} \mathrm{-} \mathrm{prevalência}$ variável da $\mathrm{IOB}$ em pacientes com $\mathrm{CHC}$ tem sido relatada na Ásia, no Japão e nos EUA' 19,20,21,22.

Pelo mecanismo de transmissão similar, a coinfecção VHB e vírus da hepatite $\mathrm{C}(\mathrm{VHC})$ é uma apresentação clínica comum, com alta prevalência do anti-VHC, mais associada ao anti-HBc positivo (anti-HBc+) do que ao $\mathrm{HBsAg}$ positivo $(\mathrm{HBsAg}+)$, ficando indefinido o impacto clínico da coinfecção $\mathrm{VHC} / \mathrm{IOB}^{4}$.

A avaliação do papel da $10 B$ em pacientes com hepatite crônica com elevação de alanina aminotransferase (ALT) detectou o VHB-DNA em 13,3\% dos pacientes com ALT normal ou ligeiramente elevada, enquanto que, com a elevação de $\operatorname{ALT}$ ( $\geq 5$ vezes valores normais), o VHB-DNA foi detectado em 63,3\% dos pacientes, o que indica que a prevalência de $\mathrm{IOB}$ seria mais alta em pacientes positivos para o $\mathrm{VHC}$ do que em negativos ${ }^{23}$.

vírus da hepatite $\mathrm{D}(\mathrm{VHD})$, único representante do gênero Deltavirus, é um vírus defectivo, que necessita da presença do VHB para provocar infecção in vivo. Em uma comunidade ameríndia da Argentina, foram identificadas, entre 46 amostras não reagentes para o VHD por ELISA, três que eram VHD-RNA+ por nested reação em cadeia da polimerase (PCR) via transcriptase reversa (RT) - RT-nested PCR. As amostras eram anti-HBC+ isolado e duas delas foram identificadas como $1 \mathrm{OB}$, evidenciando que a infecção pelo VHD pode ocorrer entre indivíduos com $\mathrm{IOB}^{24}$.

Sabe-se que o HIV altera a história natural da infecção pelo VHB. Na infecção aguda pelo VHB em pacientes portadores do HIV, as chances de esses se tornarem portadores crônicos do VHB são de cinco a seis vezes maiores do que para as pessoas com resultado negativo para HIV. Pacientes coinfectados com HIV e VHB progridem mais rapidamente para o estágio final da doença hepática, e os diferentes genótipos do VHB podem ter um impacto distinto na progressão da doença ${ }^{25}$.

$\mathrm{Na}$ análise de 191 amostras de soro de pacientes belgas coinfectados HIV/VHB, com anti-HBc+, 65,3\% apresentavam "infecção evidente" e 34,7\%, "infecção oculta". Foram detectados os genótipos A $(69,6 \%), E$, D, C e G. O genótipo A foi observado em todos os pacientes do grupo clínico e de etnias variadas, e o genótipo $E$, em pacientes africanos ${ }^{26}$.

Estudos comprovaram a existência de alta prevalência da IOB entre dialisados, entretanto a prevalência de IOB entre receptores de transplante renal é controversa ${ }^{27,28,29,30,31,32}$. A análise de 752 amostras $\mathrm{HBsAg-}$, para identificar $\mathrm{IOB}$ em hemodialisados de cinco clínicas de Recife, estado de Pernambuco, Brasil, encontrou soroprevalência de 5,7\% para o anti-HBc total+ isolado, e a IOB foi identificada em $1,5 \%$ das amostras examinadas. $O$ genótipo $A$ foi detectado em 33,3\% das amostras e o D em 66,7\%, não sendo observada nenhuma mutação ${ }^{33}$. $\bigcirc$ estudo de 207 pacientes $\mathrm{HBsAg}-$, receptores de transplante de rim, do estado do Rio de Janeiro, encontrou 1,0\% com VHB-DNA positivo, indicando presença de $\mathrm{IOB}^{34}$.

Em 2014, um estudo realizado para determinar a frequência de $\mathrm{IOB}$ entre coinfectados por HIV/VHB, com anti-HBc+, doadores de sangue em Medellín, Norte da Colômbia Ocidental, e caracterizar os genótipos virais e mutações, relatou que $\circ \mathrm{HBsAg}$ utilizado na triagem em bancos de sangue reduziu $O$ risco de transmissão de VHB por transfusão; entretanto, a descoberta de $\mathrm{IOB}$ entre doadores de sangue tornou imperativa a melhora na segurança da doação. Nesse estudo, foram analisadas 302 amostras de soro

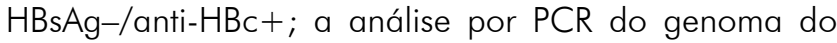


VHB identificou seis amostras $(1,98 \%)$ como IOB, todas do subgenótipo $\mathrm{F}^{35}$.

Uma pesquisa sobre $\mathrm{IOB}$ realizada com doadores de dois bancos de sangue, na Nigéria, identificou, entre 429 indivíduos, $17,0 \%$ com IOB. A carga viral foi de $<50$ cópias $/ \mathrm{mL}$ na $\mathrm{IOB}$ e predominou o genótipo $E$. Concluiu-se que a grande incidência da $\mathrm{IOB}$ era relevante em áreas de alta endemicidade e um problema geral para a segurança da doação de sangue, pela elevada prevalência detectada ${ }^{36}$.

É de conhecimento geral que os usuários de drogas ilícitas apresentam risco aumentado de infecção pelo VHB. Um estudo desenvolvido para investigar o perfil soroepidemiológico e molecular da infecção pelo VHB nesses indivíduos, na Região Centro-Oeste do Brasil, analisou 1.002 usuários que utilizavam drogas injetáveis (UDI) e não injetáveis (UDNI). A prevalência global da infecção pelo VHB foi de 15,0\%, sendo que $20,7 \%$ pertenciam ao grupo de UDI e $14,0 \%$ ao de UDNI. O índice de IOB foi de 3,6\% entre usuários anti- $\mathrm{HBc}+$, mostrando a presença de $\mathrm{IOB}$ e a necessidade de se investigar os casos $\mathrm{HBsAg}_{-}$, para controle da infecção entre esses usuários ${ }^{37}$.

Localizado na região oeste do estado do Pará, à margem direita do Rio Amazonas, fazendo parte da Mesorregião do Baixo Amazonas e da Microrregião de Óbidos, o município de Juruti, com população estimada em 52.179 habitantes pelo Instituto Brasileiro de Geografia e Estatística ${ }^{38}$ para 2016, vem sendo submetido, desde 2005, à exploração de reserva de bauxita, a qual acarretou grande migração populacional para o município. Pela possibilidade do surgimento ou do aumento da frequência de doenças influenciadas por essa exploração, particularmente quanto às hepatites virais, foi desenvolvido, entre 2007 e 2010, um projeto de pesquisa em Juruti, o qual, entre outras investigações, desenvolveu um estudo para definir a prevalência das infecções pelos vírus das hepatites. Nesse estudo foram coletadas, nos dois primeiros anos, 1.630 amostras de soro de pessoas da demanda hospitalar municipal, as quais foram submetidas à análise dos marcadores sorológicos das hepatites $A, B, C$ e $D$, por técnicas imunoenzimáticas, tendo havido prevalência de $1,4 \%$ de indivíduos com perfil de infecção pregressa ou atual pelo VHB (anti$\mathrm{HBc}$ total + isolado) ${ }^{39}$.

A Amazônia Ocidental é uma das regiões no mundo com alta prevalência da hepatite $B$, e poucos são os estudos desenvolvidos sobre a $\mathrm{IOB}$ nessa região. A detecção de indivíduos com sorologia anti-HBc total+ isolado indicou a necessidade de se conhecer a prevalência desse achado em populações amazônicas, como é o caso de Juruti. Isso poderá contribuir para a detecção, o entendimento da evolução e o prognóstico dos portadores dessa doença, principalmente porque as drogas atualmente utilizadas pelo sistema público de saúde do Brasil ainda são ineficazes para o tratamento da hepatite $B$, havendo a perspectiva de que, nos próximos anos, novas drogas venham a compor 0 arsenal para seu tratamento.
Este estudo objetivou investigar a ocorrência de IOB na população do município de Juruti. De forma específica, objetivou-se definir a soroprevalência da infecção pelo VHB; determinar a frequência de IOB; descrever as características demográficas dos portadores do VHB e dos portadores de IOB; determinar a carga viral e os genótipos em portadores do VHB-DNA/HBsAg+ selecionados; determinar a carga viral e os genótipos em portadores do VHB$\mathrm{DNA} / a n t i-\mathrm{HBC}$ total+ isolado; comparar os genótipos das amostras anti-HBc total+ isolado com as amostras $\mathrm{HBsAg}+$, identificando os genótipos circulantes na população examinada; identificar mutações na estrutura do HBsAg que permitam o escape e a não detecção pelos testes imunoenzimáticos; e detectar a presença de coinfecção da IOB com o HIV, o VHC e o VHD.

\section{MATERIAIS E MÉTODOS}

Estudo descritivo, transversal, retrospectivo, desenvolvido entre março de 2012 e abril de 2015, com amostras de soro coletadas durante a execução de projeto sobre hepatites virais no município de Juruti, oeste do estado do Pará, Brasil, pela Seção de Hepatologia (SAHEP) do Instituto Evandro Chagas (IEC), o qual foi realizado entre fevereiro de 2007 e novembro de 2010.

Foram incluídas, no presente estudo, amostras de indivíduos com sorologia $\mathrm{HBsAg}+$ e anti- $\mathrm{HBc}$ total+ isolado, selecionadas a partir do referido projeto, de forma aleatória, totalizando 3.991 amostras.

$\mathrm{Na}$ SAHEP, por técnicas imunoenzimáticas, foram realizados testes sorológicos para as hepatites $\mathrm{B}$ ( $\mathrm{HBs} A g$, anti-HBc total e anti-HBs) e C (anti-VHC) nas 3.991 amostras, utilizando-se kits comerciais dos laboratórios bioMérieux ${ }^{\circledR}$ (Marcy-l'Etoile, França) e $\mathrm{ORTHO}^{\circledR}$ (New Jersey, EUA), respectivamente.

Nas amostras $\mathrm{HBsAg}+$ e anti-HBc total+ isolado, foram pesquisados, por técnica imunoenzimática, os marcadores sorológicos anti-HBc IgM (bioMérieux ${ }^{\circledR}$, Marcy-l'Étoile, França); HBeAg (Bio-RAD ${ }^{\circledR}$, Marnes-laCoquette, França); anti-HBe (RADIM ${ }^{\circledR}$, Pomezia, Itália) e anti-VHD (bioMérieux ${ }^{\circledast}$, Marcy-l'Étoile, França). Foram considerados duvidosos os testes que apresentaram densidade óptica situada 20,0\% para cima ou para baixo do limite de cut-off.

Nas amostras anti-HBc total+ isolado, também foram realizados, na Seção de Virologia do IEC, os testes sorológicos para o anti-HIV 1/2 SYM (Symbiosys ${ }^{\circledR}$, São Paulo, Brasil). Todos os testes foram executados e interpretados conforme as indicações dos fabricantes.

Os testes de biologia molecular para o VHB foram realizados na SAHEP/IEC. Todas as amostras $\mathrm{HBsAg}+$ e anti-HBc total+ isolado foram submetidas à quantificação da carga viral por PCR em tempo real, utilizando-se o sistema automatizado Abbott m24sp/m2000rt com o kit Abbott RealTime HBV ${ }^{\circledR}$ (Abbott Laboratories, Chicago, EUA), que apresenta linearidade de $10 \mathrm{UI} / \mathrm{mL}$ a $1.000 .000 .000 \mathrm{UI} / \mathrm{mL}$. 
As amostras que apresentaram carga viral de VHB detectáveis foram submetidas à amplificação por nested PCR de um fragmento de 734 pares de base (pb) dos genes que codificam a polimerase viral e $\circ \mathrm{HBsAg}$, utilizando-se os iniciadores e condições de PCR ${ }^{40,41}$.

sequenciamento foi realizado utilizando-se ○ kit BigDye ${ }^{\circledR}$ Terminator v3.1 Cycle Sequencing (Applied Biosystems, Carlsbad, EUA) no sequenciador automático ABI 3500 (Applied Biosystems, Carlsbad, EUA), sendo utilizados os iniciadores FHBS2, RHBS2 5'- GCC ARG AGA AAC GGR CTG AGG CCC - 3', 5'LAM5 5'-TGC RYY TGT ATT CCC ATC CCA TC - 3' e RADE2M.

As sequências obtidas foram editadas e alinhadas no programa Geneious v8.1.3, juntamente com sequências dos diferentes genótipos e subgenótipos do VHB disponíveis no GenBank. O cladograma foi construído usando-se o método neighbor-joining ${ }^{42}$ Kimura 2-parâmetros no programa MEGA v6.06.

Para identificação de mutações que levassem ao escape na detecção dos testes imunoenzimáticos, fez-se a dedução de aminoácidos a partir do sequenciamento de nucleotídeos da região S/Pol, utilizando-se o programa Geneious v8.1.3. As sequências obtidas foram alinhadas com sequências de VHB do tipo "selvagem" e analisadas visualmente para detecção de mutações na região $M H R$ no gene $S$, compreendendo os aminoácidos 100 a 169. Também foram pesquisadas mutações no gene que codifica a polimerase viral e analisados os aminoácidos que fazem parte dos domínios funcionais da transcriptase reversa (domínios A-E).

As amostras positivas para anti-VHC foram submetidas à quantificação da carga viral, utilizando-se - kit Abbott RealTime $\mathrm{HCV}^{\circledR}$ (Abbott Laboratories, Des Plaines, EUA) no sistema automatizado Abbott m24sp/m2000rt. Nos casos positivos pela PCR em tempo real, foi realizado heminested $P C R$ de um fragmento de 382 pares de base (PB) do gene que codifica a NS5B para identificação do genótipo do VHC, utilizando-se os iniciadores e condições de $\mathrm{PCR}^{43,44}$.

Amostras excedentes foram armazenadas em freezer a $-70{ }^{\circ} \mathrm{C}$, as quais integram o Biorrepositório do referido estudo.

Os dados da Ficha Preliminar de Inquérito de Saúde e os resultados sorológicos foram armazenados em base de dados da SAHEP/IEC (Hepatoware). Foi determinada a distribuição espacial dos casos detectados, com base em medidas epidemiológicas que incluíram o cálculo de frequências para casos prevalentes e a relação com o perfil epidemiológico dos casos (sexo, idade, estado civil, procedência; se era vacinado contra $\circ \mathrm{VHB}$, se teve hepatite, e quais os sintomas e sinais). As análises estatísticas foram conduzidas empregando-se os softwares Epi Info ${ }^{T M}$ v7 e BioEstat v5.045. Foi utilizado o teste de significância estatística (teste exato de Fisher do programa Epi Info ${ }^{T M}$ v7, com nível de significância de $5 \%$ e intervalo de confiança - IC de 95\%), para se analisar as diferenças entre os grupos, e o aplicativo Microsoft Excel, para as representações gráficas. As amostras foram testadas sob a hipótese de nulidade $\left(\mathrm{H}_{0}\right)$ de que a infecção oculta pelo VHB não ocorre no município de Juruti; e sob a hipótese alternativa $\left(\mathrm{H}_{1}\right)$ de que a infecção oculta pelo VHB ocorre no Município.

Baseado na Resolução CNS no 466/2012 da Comissão Nacional de Ética em Pesquisa ${ }^{46}$, este projeto foi aprovado em 31 de março de 2011, pelo Comitê de Ética em Pesquisa Envolvendo Seres Humanos do IEC, com parecer de aprovação $n^{\circ}$ 010/2011 (CAAE: 0038.0.072.000-10).

\section{RESULTADOS}

Foram selecionadas 3.991 amostras de soro de indivíduos de Juruti, no período de fevereiro de 2007 a novembro de 2010, coletadas na sede do Município, no Hospital Francisco Barros (75,2\%; 3.001/3.991); na Comunidade Café Torrado (5,8\%; 230/3.991); na localidade Jauari (1,0\%; 42/3.991); na Comunidade Nova Galileia (2,8\%; 110/3.991); em Vila Muirapinima $(7,7 \% ; 307 / 3.991)$; e na invasão, às margens do Lago Jará $(7,5 \% ; 301 / 3.991)$,

Observou-se uma frequência de 62,7\% (2.501/ 3.991) para indivíduos do sexo feminino. A média de idade da população foi de $27,6 \pm 18,7$ anos (variação de 5 meses a 89 anos) e a mediana, de 25 anos de idade. A maior concentração de participantes estava na sede do Município; a maior e a menor frequência de indivíduos foram encontradas na faixa etária de 20 a 29 anos (20,8\%; 832/3.991) e entre os menores de 1 ano de idade $(0,3 \%$; 10/3.991), respectivamente.

Foi identificada prevalência de 0,5\% (21/3.991; IC 95\% 0,39-0,61) para $\mathrm{HBsAg}+$; 8,3\% (332/3.991; IC $95 \%$ 5,33-11,26) para anti-HBc total+/anti-HBs+; $1,1 \%(43 / 3.991$; IC 95\% 0,79-1,41) para anti-HBc total + isolado; e $33,6 \% \quad(1.339 / 3.991$; IC $95 \%$ $31,07-36,13)$ apresentaram resposta vacinal contra - VHB (anti-HBs+ isolado). $\bigcirc$ perfil sorológico vacinal, até os 29 anos de idade, se mostrou em $47,8 \%$ (1.135/2.375), conforme se pode visualizar na tabela 1 .

Verificou-se que, entre os indivíduos $\mathrm{HBsAg}+$, não foram encontradas amostras positivas para o anti-HBc $\lg M$, o anti-VHC ou o anti-HD. Os testes de biologia molecular identificaram que $66,7 \%$ (14/21) dos indivíduos apresentavam PCR VHB-DNA qualitativo+.

$O$ teste de carga viral realizado nas 14 amostras $\mathrm{HBsAg}+$ variou entre $<55 \mathrm{Ul} / \mathrm{mL}$ e $>38.000$ $\mathrm{UI} / \mathrm{mL}$. Em 13 dessas amostras, foi possível realizar a genotipagem do $\mathrm{VHB}$, com a detecção em 69,2\% (9/13) do genótipo $A$, subgenótipo $A 1$, e do genótipo $F$, sendo $15,4 \%$ (2/13) do subgenótipo F2 e 15,4\% (2/13) do subgenótipo F4. Nessas 13 amostras, também foram detectados 69,2\% (9/13) de subtipos sorológicos adw2 (todos do subgenótipo A1) e 30,8\% (4/13) de subtipos adw4 (dois do subgenótipo F2 e dois do F4), conforme apresentado no quadro 1. 
Tabela 1 - Soroprevalência de HBsAg +, anti-HBc total+/anti-HBs +, anti-HBc+ isolado e anti-HBs + isolado, por faixa etária, em Juruti, estado do Pará, Brasil, de fevereiro de 2007 a novembro de 2010

\begin{tabular}{|c|c|c|c|c|c|c|c|c|c|c|c|c|}
\hline \multirow{2}{*}{$\begin{array}{l}\text { Faixa etária } \\
\text { (anos) }\end{array}$} & \multicolumn{2}{|c|}{$\begin{array}{l}\text { População } \\
\text { examinada }\end{array}$} & \multicolumn{2}{|c|}{$\mathrm{HBsAg}+$} & \multicolumn{2}{|c|}{$\begin{array}{c}\text { Anti-HBc total+/ } \\
\text { anti-HBs }+\end{array}$} & \multicolumn{2}{|c|}{$\begin{array}{l}\text { Anti-HBc total+ } \\
\text { isolado }\end{array}$} & \multicolumn{2}{|c|}{$\begin{array}{l}\text { Anti-HBs }+ \\
\text { isolado }\end{array}$} & \multicolumn{2}{|c|}{ Suscetíveis } \\
\hline & $\mathrm{N}$ & $\%$ & $N$ & $\%$ & $\mathrm{~N}$ & $\%$ & $\mathrm{~N}$ & $\%$ & $\mathrm{~N}$ & $\%$ & $\mathrm{~N}$ & $\%$ \\
\hline$<1$ & 10 & 0,3 & - & - & 1 & 10,0 & - & - & 4 & 40,0 & 5 & 50,0 \\
\hline $1-4$ & 317 & 7,9 & - & - & 2 & 0,6 & - & - & 197 & 62,2 & 118 & 37,2 \\
\hline $5-9$ & 488 & 12,2 & - & - & 2 & 0,4 & 1 & 0,2 & 271 & 55,6 & 214 & 43,8 \\
\hline $10-19$ & 728 & 18,2 & 2 & 0,3 & 7 & 1,0 & 4 & 0,5 & 418 & 57,4 & 297 & 40,8 \\
\hline $20-29$ & 832 & 20,8 & 3 & 0,4 & 34 & 4,1 & 3 & 0,4 & 245 & 29,4 & 547 & 65,7 \\
\hline $30-39$ & 618 & 15,5 & 5 & 0,8 & 69 & 11,2 & 3 & 0,5 & 103 & 16,7 & 438 & 70,8 \\
\hline $40-49$ & 393 & 9,9 & 5 & 1,3 & 60 & 15,3 & 6 & 1,5 & 37 & 9,4 & 285 & 72,5 \\
\hline $50-59$ & 331 & 8,3 & 3 & 0,9 & 74 & 22,4 & 8 & 2,4 & 32 & 9,7 & 214 & 64,6 \\
\hline$\geq 60$ & 274 & 6,9 & 3 & 1,1 & 83 & 30,3 & 18 & 6,6 & 32 & 11,7 & 138 & 50,3 \\
\hline Total & 3.991 & 100,0 & 21 & 0,5 & 332 & 8,3 & 43 & 1,1 & 1.339 & 33,6 & 2.256 & 56,5 \\
\hline
\end{tabular}

N: População examinada; Sinal convencional utilizado: - dado numérico igual a zero, não resultante de arredondamento; HBsAg+: portador do VHB; Anti-HBc total+/anti-HBs +: perfil de infecção pregressa pelo VHB; Anti-HBs+ isolado: perfil compatível com proteção vacinal; Anti-HBc total+ isolado: perfil compatível com infecção pregressa ou atual pelo VHB.

\begin{tabular}{|c|c|c|c|c|c|c|c|}
\hline $\begin{array}{c}\mathrm{N}^{0} \text { da amostra } \\
(\mathrm{HBsAg}+)\end{array}$ & Sexo & Idade & $\begin{array}{c}\text { PCR VHB-DNA } \\
\text { qualitativo }\end{array}$ & $\begin{array}{l}\text { PCR VHB-DNA } \\
\text { quantitativo }\end{array}$ & $\begin{array}{c}\text { Genótipo } \\
\text { VHB }\end{array}$ & $\begin{array}{c}\text { Subgenótipo } \\
\text { VHB }\end{array}$ & Subtipo \\
\hline 151391 & $\mathrm{~F}$ & 63 & Positivo & $<57 \mathrm{UI} / \mathrm{mL}$ & $\mathrm{F}$ & F4 & adw4 \\
\hline 151680 & $\mathrm{~F}$ & 39 & Positivo & $<57 \mathrm{Ul} / \mathrm{mL}$ & $A$ & $\mathrm{Al}$ & adw2 \\
\hline 155002 & $\mathrm{~F}$ & 44 & Positivo & 142 UI/mL & $A$ & $\mathrm{~A} 1$ & adw2 \\
\hline 156846 & $M$ & 36 & Positivo & 182 UI/mL & $A$ & $\mathrm{Al}$ & adw2 \\
\hline 157021 & $\mathrm{~F}$ & 21 & Positivo & $426 \mathrm{UI} / \mathrm{mL}$ & $A$ & $\mathrm{Al}$ & adw2 \\
\hline 159723 & M & 55 & Positivo & $72 \mathrm{UI} / \mathrm{mL}$ & A & $\mathrm{Al}$ & adw2 \\
\hline 159808 & M & 61 & Positivo & $>38.000 \mathrm{UI} / \mathrm{mL}$ & A & $\mathrm{Al}$ & adw2 \\
\hline 160077 & M & 47 & Positivo & $<57 \mathrm{UI} / \mathrm{mL}$ & $\mathrm{F}$ & F2 & adw4 \\
\hline 167207 & M & 21 & Positivo & $988 \mathrm{UI} / \mathrm{mL}$ & $A$ & $\mathrm{Al}$ & adw2 \\
\hline 167425 & M & 43 & Positivo & $2.678 \mathrm{UI} / \mathrm{mL}$ & $A$ & $\mathrm{Al}$ & adw2 \\
\hline 167486 & M & 46 & Positivo & $61 \mathrm{UI} / \mathrm{mL}$ & $\mathrm{F}$ & $\mathrm{F} 4$ & adw4 \\
\hline 173518 & $\mathrm{~F}$ & 18 & Positivo & $<55 \mathrm{UI} / \mathrm{mL}$ & NR & NR & NR \\
\hline 173538 & $\mathrm{~F}$ & 31 & Positivo & $1.730 \mathrm{UI} / \mathrm{mL}$ & A & $A 1$ & adw2 \\
\hline 176439 & $\mathrm{~F}$ & 25 & Positivo & $7.848 \mathrm{UI} / \mathrm{mL}$ & $\mathrm{F}$ & F2 & adw4 \\
\hline
\end{tabular}

NR: Não realizado, por esgotamento da amostra.

Quadro 1 - Genótipos, subgenótipos e subtipos do VHB-DNA identificados entre 14 amostras de indivíduos HBsAg+, em Juruti, estado do Pará, Brasil, de fevereiro de 2007 a novembro de 2010

Quanto à prevalência de genótipos, o subgenótipo Al foi o mais prevalente $64,3 \%$ (9/14), principalmente na faixa etária entre 30 e 39 anos. Houve a detecção dos subgenótipos F2 e F4, sendo que o subgenótipo F2 ocorreu em indivíduos de 25 e 47 anos e o F4 em indivíduos de 46 e 63 anos.

O cladograma desenvolvido para as amostras de VHB teve por base o alinhamento de sequências da região S/Pol (742 pb), utilizando-se o método neighbor-joining (Kimura 2-parâmetros) e o teste de bootstrap de 1.000 réplicas. Nove amostras agruparam com sequências do subgenótipo $A l$, que é 0 mais frequente no continente americano. Também foram identificadas quatro sequências de VHB, genótipo $F$, sendo duas do subgenótipo F2 e duas do F4 (Figura 1). 


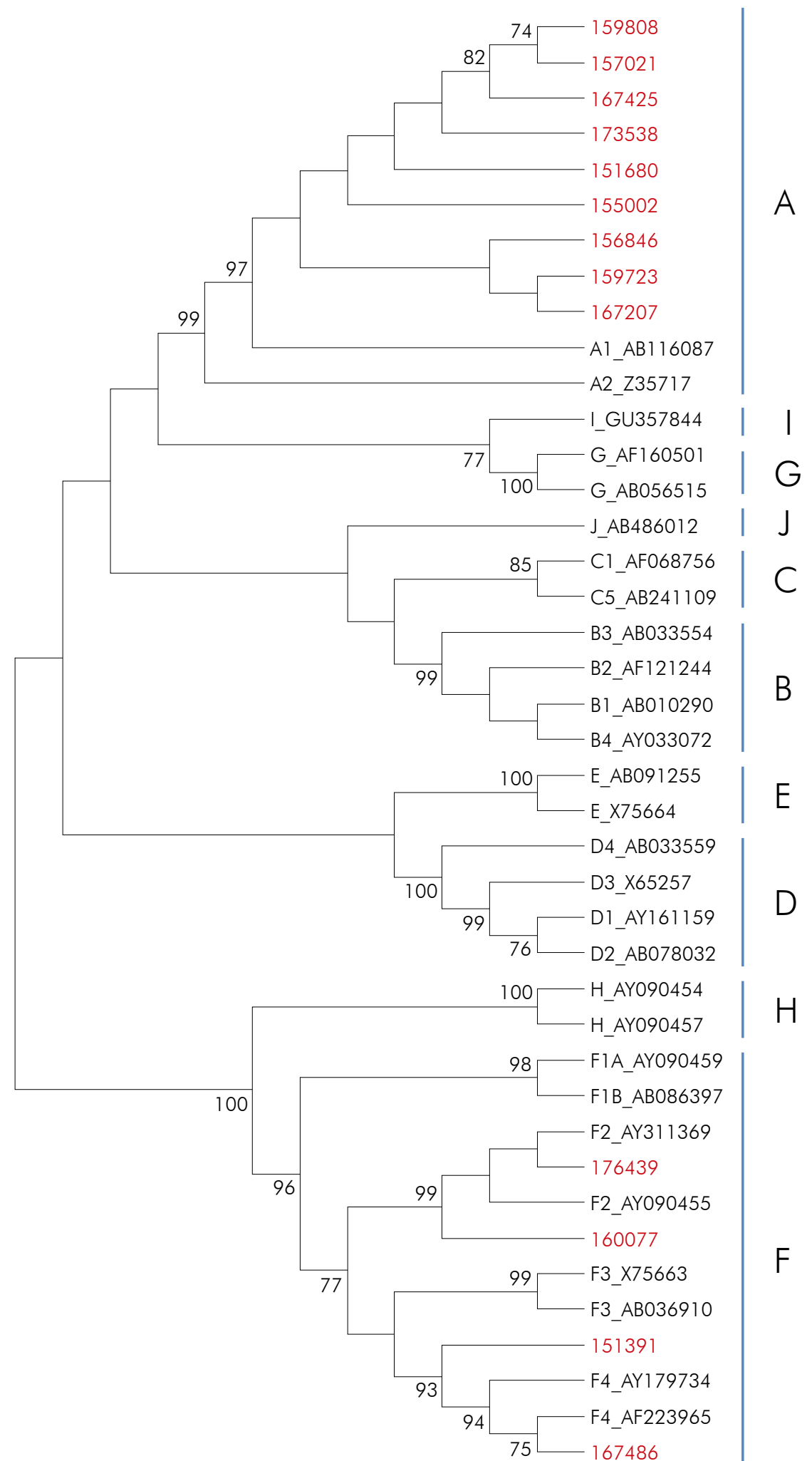

Sequências obtidas do GenBank estão identificadas com o número de acesso. Valores de bootstrap superiores a 70,0\% são mostrados na árvore.

Figura 1 - Cladograma da região S/Pol do VHB inferida com método neighborjoining (Kimura 2-parâmetros)

A análise da região do domínio $C$ da polimerase e da determinante "a" do HBsAg não detectou a presença de mutações; entretanto, quando foram realizadas as análises de outras regiões, foram encontradas duas mutações. Uma na posição 169 , com substituição de uma arginina por uma prolina (R169P) no gene $S$, da amostra 151680 (Figura 2). A amostra pertencia a uma paciente de 39 anos de idade, casada, comerciante, natural do município de Oriximiná, oeste do estado do Pará, oligossintomática, com hepatoesplenomegalia, que havia recebido o esquema completo de vacinação e apresentava HBsAg + desde 2003. Outra mutação ocorreu no domínio $D$ da polimerase, com substituição de uma serina por ácido aspártico (r+S238D) da 
transcriptase reversa, na amostra 151391 (Figura 3). Essa amostra pertencia a uma paciente com 63 anos de idade, casada, aposentada, procedente de Juruti, oligossintomática, sem história anterior de infecção pelo $\mathrm{VHB}$, e que havia recebido o esquema vacinal completo contra o VHB.

A análise das características demográficas dos 14 pacientes $\mathrm{HBsAg}+$ com VHB-DNA+ mostrou ausência de portadores do VHB abaixo dos 10 anos de idade; $50,0 \%(7 / 14)$ eram do sexo masculino; $64,3 \%(9 / 14)$ eram casados; $57,1 \%$ (8/14) procediam de Juruti, $21,4 \%(3 / 14)$ de outras cidades do Pará (Óbidos, Oriximiná e Rurópolis) e 21,4\% (3/14) dos estados do Amazonas (Parintins), Ceará (Uruburetama) e Paraná (Diamante D'Oeste); 78,6\% (11/14) informaram não serem vacinados contra o VHB; 92,9\% (13/14) desconheciam se haviam contraído hepatite; e 50,0\% (7/14) responderam afirmativamente sobre a presença de sintomas e sinais.

Apenas a variável "vacinado contra a hepatite B" mostrou significância estatística, com $p=0,04$, e os indivíduos não vacinados contra o VHB tiveram um risco (razão de prevalência) 0,32 vezes maior de serem infectados pelo VHB, quando comparados aos vacinados.

Do total de 43 amostras anti-HBc total+ isolado, não foi detectado o marcador sorológico anti-HBc IgM. Os testes de biologia molecular dessas amostras detectaram 9,3\% (4/43) de indivíduos VHB-DNA+, com carga viral entre $<15 \mathrm{Ul} / \mathrm{mL}$ e $48 \mathrm{UI} / \mathrm{mL}$. A baixa carga viral encontrada impossibilitou a genotipagem e sequenciamento dessas amostras (Quadro 2).

Nas amostras anti-HBc total+ isolado, a pesquisa detectou prevalência do anti-VHC de 4,7\% (2/43), tendo sido confirmado por RT-PCR, como portador do VHC, genótipo 1a, um indivíduo do sexo masculino, com 80 anos de idade, assintomático, casado, residente na área urbana de Juruti. Nessas amostras, a pesquisa do anti-HD se mostrou negativa. E não foram detectadas sorologias anti-HIV positivo.

Em relação à distribuição de pacientes anti$\mathrm{HBc}$ totalt isolado com VHB-DNA+, a presença do vírus foi detectada a partir dos 40 anos de idade, com maior frequência entre os indivíduos a partir de 60 anos.

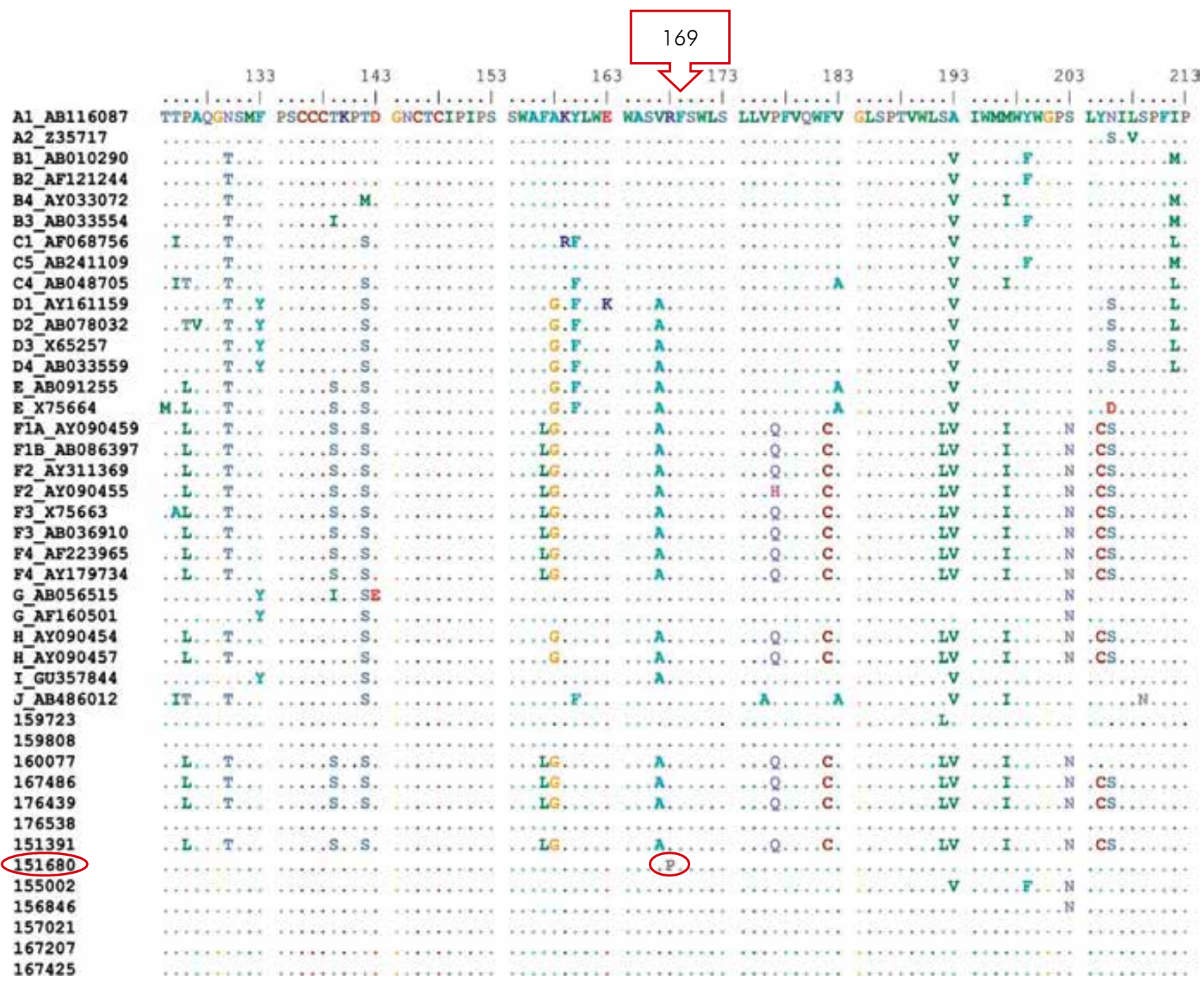

Figura 2 - Alinhamento da sequência de aminoácidos da região S do VHB das amostras do estudo e as obtidas do GenBank 
$\begin{array}{lllllllll}152 & 162 & 172 & 182 & 192 & 202 & 212 & 222 & 232 \quad 5242\end{array}$

A1 $\mathrm{AB} 116087$

A2 235717

B1 AB010290

B2 AF121244

B4 AY033072

B3 $\mathrm{AB} 033554$

C1 AF068756

C5 $A B 241109$

$C 4-\mathrm{AB} 048705$

D1 $A$ AY161159

D2_AB078032

D3 X65257

D4 AB033559

E $\bar{A}$ B091255

EX75664

FIA AY090459

F1B_AB086397

F2 AY 311369

F2 AY090455

$\mathrm{F}^{3} \times 75663$

F3 AB036910

F4 AF223965

F4 AY179734

G_AB 056515

G AF160501

H AY090454

H_AY090457

I_GU357844

J_AB486012

$1 \overline{5} 9723$

159808

160077

167486

176439

176538

151391

151680

155002

156846

157021

167207

167425

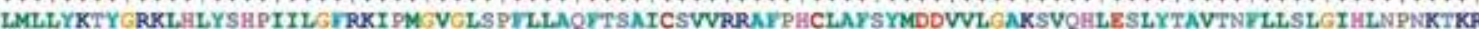

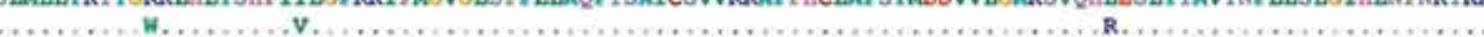

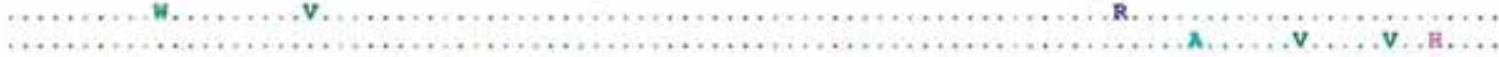

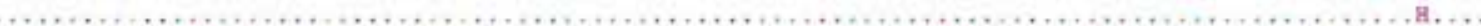

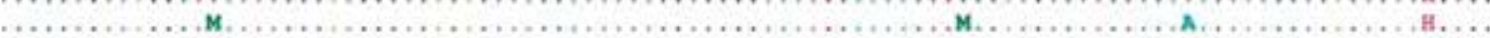

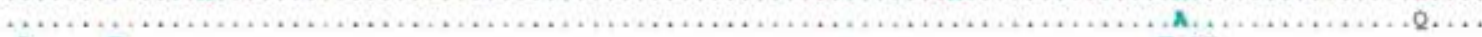

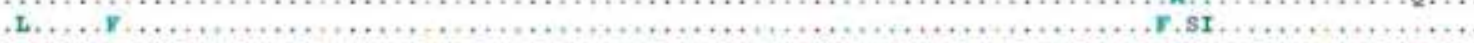

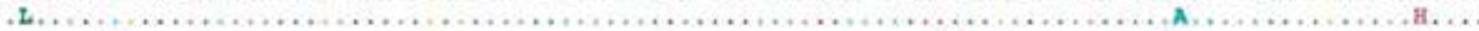

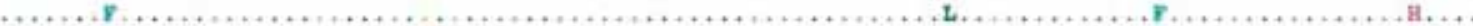

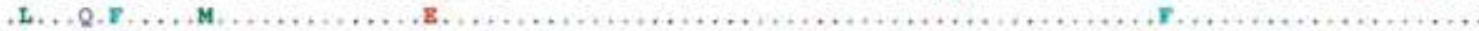

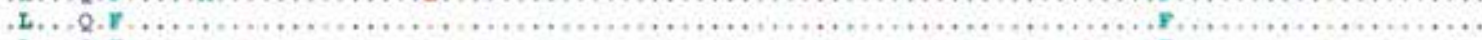

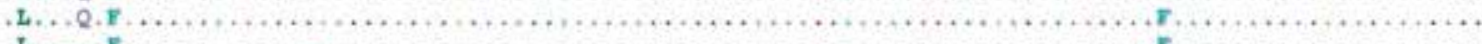

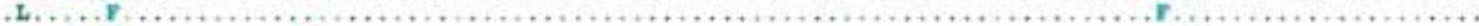

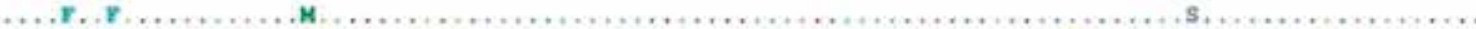

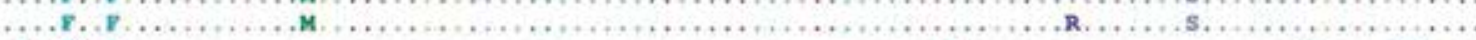

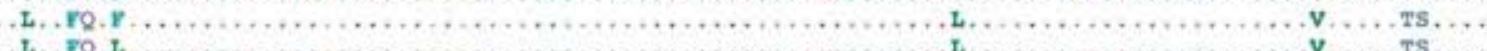

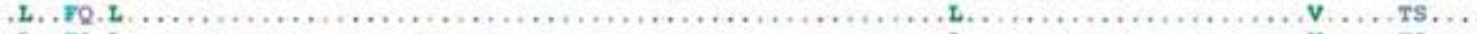

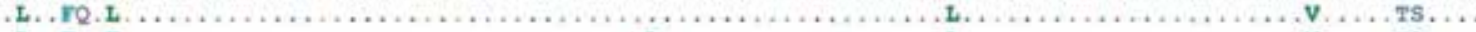

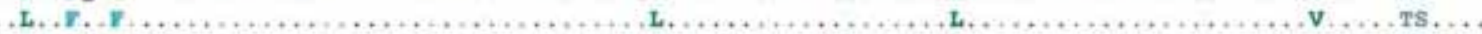

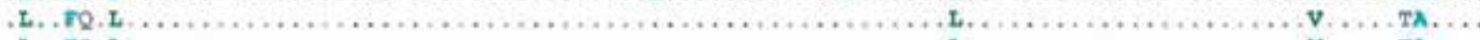

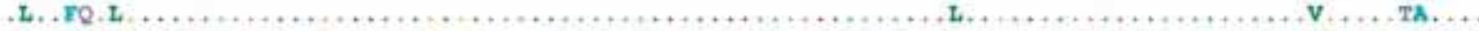

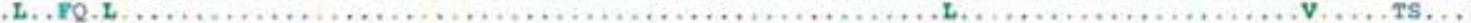

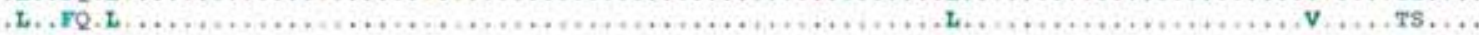

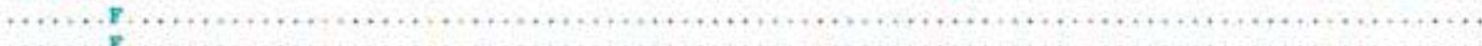

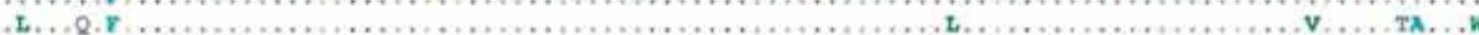

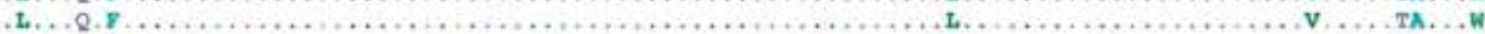

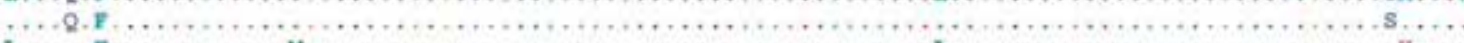

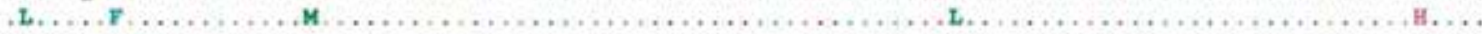

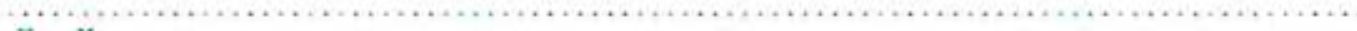

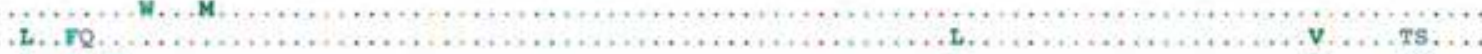

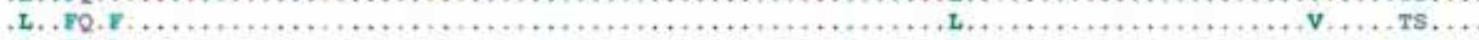

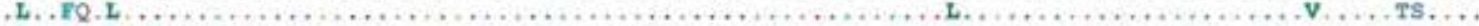

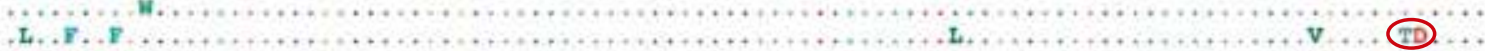

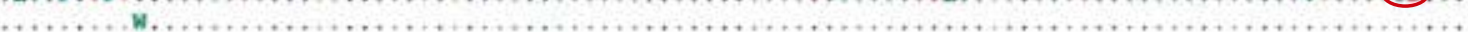

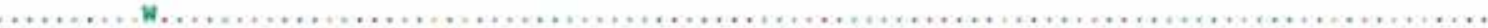

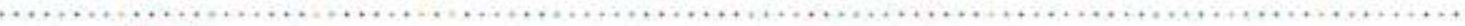

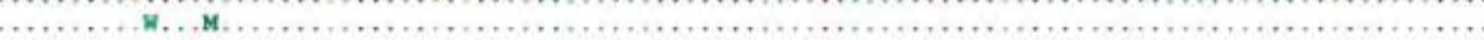

................

Figura 3 - Alinhamento da sequência de aminoácidos da região Pol do VHB das amostras do estudo e as obtidas do GenBank

\begin{tabular}{|ccccc|}
\hline $\begin{array}{c}N^{\circ} \text { da amostra } \\
\text { (anti-HBc total+) }\end{array}$ & Sexo & Idade & $\begin{array}{c}\text { PCR VHB-DNA } \\
\text { qualitativo }\end{array}$ & $\begin{array}{c}\text { PCR VHB-DNA } \\
\text { quantitativo }\end{array}$ \\
\hline 159660 & F & 49 & Positivo & NR \\
159810 & F & 52 & Positivo & $48 \mathrm{UI} / \mathrm{mL}$ \\
167158 & M & 65 & Positivo & $21 \mathrm{UI} / \mathrm{mL}$ \\
170172 & F & 77 & Positivo & $<15 \mathrm{Ul} / \mathrm{mL}$ \\
\hline
\end{tabular}

NR: Não realizado, por esgotamento da amostra.

Quadro 2 - Testes de PCR VHB-DNA qualitativo e quantitativo em quatro amostras anti-HBc total+ isolado, em Juruti, estado do Pará, Brasil, de fevereiro de 2007 a novembro de 2010

\section{DISCUSSÃO}

A IOB é uma entidade clínica desafiante, reconhecida por duas principais características: ausência de HBsAg e baixa replicação viral. Entretanto, nas décadas de 1990 e 2000, houve um notável progresso na compreensão de suas implicações clínicas. Percebeu-se que técnicas diagnósticas apropriadas deveriam ser adotadas, pois ensaios sensíveis de amplificação do VHB-DNA são considerados como o padrão ouro para detecção da IOB. Foi identificado que fatores virais e fatores do hospedeiro estariam implicados na patogênese da IOB, embora alguns pesquisadores ainda achem que a infectividade pela IOB por transfusão é limitada. Por essas razões, vários aspectos da transmissão da $1 \mathrm{OB}$, sua infecciosidade e relação com o desenvolvimento de doenças crônicas do fígado e CHC ainda necessitam ser investigados ${ }^{28,29}$.

A IOB, conceituada como a detecção do VHB-DNA no soro ou no fígado por teste diagnóstico sensível, em pacientes $\mathrm{HBsAg}$ - com ou sem marcadores sorológicos de exposição prévia viral, parece ser elevada entre pacientes sob alto risco de infectar-se pelo $\mathrm{VHB}$ e com doença hepática. Pode originar-se tanto pela contaminação com sangue como pela doação de 
órgãos e funcionar como elemento desencadeador de reativação após uma hepatite, dependendo das características do vírus e de fatores do hospedeiro ${ }^{30}$.

Este estudo foi desenvolvido com o objetivo de investigar a ocorrência de $\mathrm{IOB}$ em uma amostra de população de Juruti, entre fevereiro de 2007 e novembro de 2010. A presença de portadores do VHB foi comprovada nessa população pela detecção de $0,5 \%$ de amostras $\mathrm{HBsAg}+; 8,3 \%$ dos indivíduos apresentaram perfil de infecção pregressa pelo VHB, com anti-HBc total+/anti-HBs+; 1,1\% dos examinados apresentaram perfil compatível de infecção pregressa ou atual pelo $\mathrm{VHB}$, com anti-HBc totalt isolado; e 33,6\% tiveram resposta vacinal contra o $\mathrm{VHB}$ (anti-HBs+ isolado).

A soroprevalência de 0,5\% (IC 95\% 0,39-0,61) de portadores do vírus $(\mathrm{HBs} A g+)$ encontrada na população de Juruti o classificou como de baixa endemicidade para o VHB, resultado semelhante ao encontrado no "Estudo de prevalência de base populacional das infecções pelos vírus das hepatites $A, B$ e C", realizado entre 2005 e 2009, nas 26 capitais brasileiras e no Distrito Federal, que mostrou prevalência sorológica para o HBsAg de 0,37\% (IC 95\% 0,25-0,50), classificando o conjunto das capitais do Brasil como de baixa endemicidade para $\circ \mathrm{VHB}^{47}$.

Entre as 21 amostras $\mathrm{HBsAg}+$, não foram detectados casos agudos de infecção pelo VHB, nem foram encontrados indivíduos portadores de infecção por VHC e VHD, o que traduz a baixa endemicidade desses vírus na região. A pesquisa do VHB-DNA dessas amostras foi positiva em 66,7\%, e a carga viral das amostras positivas variou entre $<55 \mathrm{Ul} / \mathrm{mL}$ e > $38.000 \mathrm{Ul} / \mathrm{mL}$, possibilitando a realização de genotipagem, constatando-se que nove delas apresentavam subgenótipo $A 1$, duas eram do subgenótipo F2 e duas do subgenótipo F4, concluindo-se que o subgenótipo $A 1$ era $\circ$ mais prevalente na amostra estudada.

A identificação dos genótipos do VHB é importante para se estimar a progressão da doença e para planejar o tratamento. Segundo levantamento de diversos estudos sobre a distribuição dos genótipos e subgenótipos do VHB no mundo, o genótipo $A$ apresenta tendência para cronicidade e é mais frequente na África Subsaariana, no Norte da Europa e na África Ocidental; os genótipos B e C são característicos da Ásia, e as mutações são mais frequentemente encontradas no genótipo C; o D predomina na África, na Europa, nos países do Mediterrâneo e na Índia, sendo frequente tanto a evolução para cronicidade como para o surgimento de mutações; o genótipo $E$ foi descrito em estudos na África Central e na Arábia Saudita; o F em estudos na Tunísia, no Brasil e na Espanha; o genótipo $G$ foi relatado na França, na Alemanha e nos EUA, em coinfecção com outros genótipos; o $\mathrm{H}$ é comumente encontrado nas Américas do Sul e Central, também relacionado a coinfecções; o genótipo I foi recentemente relatado no Vietnã e Laos, e o J foi identificado em ilhas do Japão ${ }^{48}$.
Um estudo envolvendo 40 hemodialisados, no estado de Santa Catarina, encontrou o genótipo D $(57,1 \%)$ como o mais prevalente, seguindo-se o A $(30,6 \%)$ e o F $(12,2 \%)$; no estado do Rio Grande do Sul, houve maior prevalência do genótipo D $(60,0 \%)$, e também foram detectados os genótipos A $(34,0 \%)$ e F $(5,0 \%)$; no estado do Paraná, os genótipos D $(82,9 \%)$ e $A(14,1 \%)$ foram os mais frequentes ${ }^{49,50,51}$.

exame de 121 indivíduos, no Rio de Janeiro, detectou 68,0\% com genótipo A, 15,0\% com genótipo $F$ e 14,0\% com genótipo D. A análise de 60 pacientes, em Recife, identificou maior prevalência dos subgenótipos Al $(79,0 \%)$ e F2 $(12,0 \%)^{52,53}$.

$\mathrm{Na}$ Amazônia Oriental, um estudo relatou prevalência do genótipo A de 81,8\%, 89,5\% e 93,7\% em pacientes assintomáticos, sintomáticos com $\mathrm{HBeAg}+$ e sintomáticos com $\mathrm{HBeAg}-$, respectivamente. Outro estudo realizado em Belém, no Pará, encontrou, entre 40 pacientes, os genótipos A1 (87,5\%), A2 (7,5\%) e D $(5,0 \%)^{54,55}$.

Na Amazônia Ocidental, detectou-se, entre 34 portadores de $\mathrm{HBsAg}+$, prevalência dos genótipos A $(73,5 \%)$ e $F(26,5 \%)^{56}$. A análise retrospectiva de 14 amostras de pacientes que desenvolveram hepatite fulminante e óbito na Amazônia Ocidental, entre 1978 e 1989, encontrou os genótipos $F(50,0 \%)$, A $(28,6 \%)$ e D $(21,4 \%)^{41}$. Outro estudo desenvolvido entre indivíduos $\mathrm{HBsAg}+$ de áreas urbana, rural e indígena do município de Lábrea, Amazônia Ocidental, mostrou que, em 86 amostras $\mathrm{HBsAg}+, 39$ apresentaram VHB-DNA positivo, sendo detectada prevalência do genótipo A $(60,0 \%)$ e presença dos genótipos D $(35,0 \%)$ e $F(5,0 \%)^{57}$. Nesse mesmo estudo, foi constatado que, entre nove amostras de indígenas, $44,4 \%$ eram genótipo A e 55,6\% genótipo $D^{57}$. Todas as pesquisas apresentadas, inclusive a realizada em Juruti, ratificam a informação de que, no Brasil, os genótipos $A, D$ e $F$ são os mais frequentes.

A pesquisa realizada em Juruti detectou nove $(69,2 \%)$ subtipos sorológicos adw2 (todos de pacientes com subgenótipo A1) e quatro (30,8\%) subtipos adw4 (dois do genótipo F2 e dois do F4). Um estudo de prevalência das hepatites B e $C$ entre mineradores da Amazônia brasileira, expostos à malária, encontrou os subtipos adw2 (59,0\%), adw4 $(8,1 \%)$, ayw3 $(8,1 \%)$ e ayw2 $(5,4 \%)^{58}$. Entre pacientes com clínica evidente de hepatite, atendidos no sistema público de saúde de Goiânia, estado de Goiás, sobre a soroprevalência de infecção pelo VHB, foram identificados os subtipos adw2 (62,7\%), ayw3 (23,5\%), ayw2 $(9,8 \%)$ e adw4 (3,9\%) ${ }^{59}$. Em contrapartida, em pacientes hospitalizados em Porto Alegre, estado do Rio Grande do Sul, foram encontrados principalmente os subtipos ayw $(60,4 \%)$ em pacientes com genótipo $D, \operatorname{adw}(34,0 \%)$ em pacientes com genótipo $A$ e adw4 $(5,4 \%)$ em pacientes com genótipo $F$, evidenciando que a distribuição dos genótipos e subtipos virais encontrados nos diferentes estudos pode refletir o padrão de ocupação do vírus nas diferentes regiões do país ${ }^{51}$. 
$\mathrm{Na}$ presente pesquisa, foram encontradas duas mutações. Uma na posição 169, com substituição de uma arginina por uma prolina (R169P) no gene $S$, da amostra 151680, localizada na maior região hidrofílica (MHR) da proteína S, entre os aminoácidos 103 e 173; entretanto fora da região da determinante "a" (entre os aminoácidos 124-147), principal epítopo para induzir uma resposta imune protetora, correlacionada com a redução da secreção do HBsAg e da partícula viral.

Mutações na região pré-S/S têm sido relatadas em muitas regiões do mundo, entretanto podem ocorrer naturalmente ou surgir durante terapia antiviral, pelo uso da imunoglobulina ou pela vacinação. Tais mutações estão fortemente relacionados à antigenicidade do $\mathrm{HBsAg}$, podendo resultar em variações antigênicas e permitir o escape vacinal do $\mathrm{VHB}$, sendo conhecidas como "mutações de escape vacinal".

O HBsAg é um importante marcador diagnóstico, estando o seu nível de expressão relacionado com a eficácia do tratamento antiviral. A mutação mais comum encontrada na região $S$ do $\mathrm{VHB}$ é a substituição da glicina pela arginina no códon 145 do HBsAg (G145R), ou de aspartato pela alanina no códon 144 (D144A) ${ }^{60}$. A outra mutação foi encontrada no domínio D, com substituição de uma serina por ácido aspártico (rtS238D) da transcriptase reversa, na amostra 151391, que pode estar potencialmente correlacionada com mutação de resistência aos antivirais adefovir e entecavir, pois alguns estudos relacionaram essas mutações à progressão da doença hepática e às terapias antivirais utilizadas ${ }^{61,62}$.

Um estudo sobre a resistência ao adefovir e entecavir no tratamento da hepatite B crônica mostrou que a resistência ao adefovir está geralmente associada ao surgimento de mutação no códon 236 ( $r+N 236 T)$ ou no códon 181 (rtA181V) do gene da polimerase do VHB. O adefovir, quando utilizado em monoterapia no primeiro ano de tratamento, costuma desenvolver resistência, e, a partir do segundo, terceiro, quarto e quinto anos, pode-se observar o surgimento de cepas resistentes em 3,0\%, 11,0\%, 18,0\% e 29,0\% dos pacientes, respectivamente ${ }^{63}$. A utilização de métodos mais sensíveis de detecção possibilitou encontrar mutação de resistência ao adefovir, após um ano de uso, chegando a 20,0\% após o segundo ano; essa resistência foi encontrada, principalmente, em pacientes resistentes à monoterapia pela lamivudina ${ }^{64}$.

Quanto ao entecavir, o surgimento de resistência em pacientes que nunca receberam tratamento apresentou-se rara, pela eficiente capacidade de supressão viral e a alta barreira genética proporcionada pelo mesmo. $\bigcirc$ estudo ETV-60 demonstrou incidência cumulativa de resistência em cinco anos de apenas $1,2 \%$. Em pacientes resistentes à lamivudina, verificouse resistência em menos de $2,0 \%$ dos pacientes durante terapia por um ano ${ }^{65}$.

Do total de 3.991 amostras examinadas, entre as $43(1,1 \%)$ que apresentavam anti-HBc total+ isolado, foi encontrada prevalência de anti-VHC em $4,7 \%$ (2/43) dos indivíduos e confirmado, por RT-PCR, um portador do VHC, genótipo la, com VHB-DNA negativo, o que revela que, nessa população, a IOB não era expressiva com relação à hepatite crônica $C$.

Se a infecção pelo VHC está associada ao aumento do risco de $\mathrm{CHC}$, então a coinfecção ativa $\mathrm{VHB} / \mathrm{VHC}$ poderia aumentar esse risco, permanecendo indeterminado o papel patogênico da IOB no $\mathrm{CHC}$, relacionado ao $\mathrm{VHC}$. $\bigcirc$ fato de se haver encontrado - VHB-DNA em 14,8\% dos pacientes HBsAg negativo/VHC positivo e em 15,0\% de 100 adultos saudáveis $\mathrm{HBs} A g$ negativo/ $\mathrm{VHC}$ negativo indicou que não havia significado clínico com a hepatite crônica $C$, em áreas onde a infecção pelo VHB era endêmica ${ }^{66}$.

Nas amostras anti-HBc total+ isolado, a pesquisa do anti-HD foi negativa, à semelhança do encontrado nas amostras $\mathrm{HBsAg}+$, permitindo caracterizar a baixa endemicidade do VHD nessa população. Um estudo sobre a prevalência sorológica e as características moleculares do VHD, dentro de uma comunidade ameríndia da Argentina, identificou, entre 46 amostras VHD negativo por ELISA, três VHD-RNA positivo por RT-nested PCR. Essas amostras eram anti-HBc positivo isolado, e duas delas foram identificadas como IOB. Todas as sequências foram identificadas como VHD genótipo 1, mas exibiam diferenças de nucleotídeos que codificavam a região $\mathrm{HDAg}-\mathrm{L}$, com mutações nos códons 197 e 201, responsável, segundo relatado, por promover in vitro uma interação inadequada com $\mathrm{HBsAg}$, evidenciando que a infecção pelo VHD pode ocorrer entre indivíduos com $\mathrm{IOB}^{24}$

Em todas as amostras anti-HBc total+ isolado, foi pesquisado o anti-HIV, com resultados negativos, muito embora tenha sido demonstrado que coinfectados $\mathrm{VHB} / \mathrm{HIV}$ podem evoluir para IOB, com baixa carga viral e HBsAg não detectável, necessitando de diagnóstico específico pela pesquisa do VHB-DNA ${ }^{67}$. Um estudo desenvolvido em Manaus, estado do Amazonas, mostrou que a probabilidade de se encontrar $\mathrm{IOB}$ foi quatro vezes maior entre os indivíduos HIV reativos, sugerindo a possibilidade da associação entre indivíduos portadores de HIV e $\mathrm{IOB}^{68}$.

VHB-DNA foi encontrado em 9,3\% (4/43) das amostras anti-HBc total+ isolado, com carga viral entre < $15 \mathrm{Ul} / \mathrm{mL}$ e $48 \mathrm{UI} / \mathrm{mL}$, impossibilitando a realização da genotipagem e sequenciamento dessas amostras, o que gerou dificuldades para comparar os genótipos das anti-HBc total+ isolado com as $\mathrm{HBsAg}+$ e identificar os genótipos circulantes na população examinada. Essa questão justifica-se tanto pela baixa carga viral como pela diferença na sensibilidade das metodologias, pois a PCR convencional costuma ser menos sensível que a PCR em tempo real, utilizada para a detecção/ quantificação ${ }^{68}$. No presente estudo, a metodologia de PCR utilizada no laboratório tinha sensibilidade de $50 \mathrm{UI} / \mathrm{mL}$.

A prevalência do VHB é definida pelos testes realizados entre os pacientes; entretanto, a aproximação diagnóstica apresenta-se inadequada, pois a descoberta da IOB requer ensaios de alta sensibilidade e especificidade, com um limite de 
detecção $<10 \mathrm{UI} / \mathrm{mL}$ para VHB-DNA e $<0,1 \mathrm{mg} / \mathrm{mL}$ para $\mathrm{HBsAg}^{69}$.

A análise das características demográficas das amostras $\mathrm{HBsAg}+$ /NHB-DNA+ não revelou significância estatística entre as variáveis analisadas, à exceção da variável relacionada à informação sobre a vacinação contra $\bigcirc \mathrm{VHB}$, que foi estatisticamente significante. Entre as amostras anti-HBc+NHB-DNA+, $75,0 \%$ dos indivíduos examinados não referiram ter sido vacinados contra o VHB; entretanto, não foi possível realizar testes estatísticos, pelo reduzido número de resultados encontrados.

Um estudo, para investigar a prevalência de $\mathrm{IOB}$ e de genótipos de VHB entre crianças mexicanas com hepatite clínica, avaliou 215 delas, por meio de marcadores sorológicos do VHB e do VHB-DNA. $A$ infecção pelo $V H B$ foi encontrada em $11,2 \%$ das crianças com hepatite clínica, com VHB-DNAt, e a IOB foi identificada em $87,5 \%$ dos casos, entre os quais $12,5 \%$ eram $\mathrm{VHB}-\mathrm{DNA}+$, com $\mathrm{HBsAg}-$. A IOB foi mais frequente nas que não tinham sido vacinadas contra hepatite $B$ do que naquelas que haviam sido vacinadas, o que ressalta a importância do diagnóstico molecular da infecção pelo VHB em crianças com hepatite clínica, enfatizando a necessidade da vacinação contra a hepatite $B^{70}$.

A cobertura vacinal contra $\circ \mathrm{VHB}$ registrada pelo Departamento de Informática do Sistema Único de Saúde, no período de fevereiro de 2007 a novembro de 2010, período no qual foram coletadas as amostras do presente estudo, entre menores de 29 anos de idade, foi de 71,2\%; na Região Norte, de 85,8\%; no estado do Pará, de 79,8\%; e de 81,6\% para o município de Juruti ${ }^{71}$. Os percentuais estiveram sempre abaixo do que preconiza o Ministério da Saúde, o qual recomenda que uma série de três doses da vacina deve induzir níveis protetores de anti-HBs em mais de 95,0\% das crianças e adolescentes e em cerca de 90,0\% dos adultos saudáveis ${ }^{72}$.

No presente estudo, foram identificados $56,5 \%$ de indivíduos suscetíveis ao VHB, que poderiam ser beneficiados por meio da vacinação. A elevada prevalência de suscetíveis associada à baixa prevalência do VHB encontrada identificou a necessidade de ampliação das atividades de prevenção e controle do $\mathrm{VHB}$, principalmente em relação à vacinação que, no Brasil, a partir de 2016, está disponível para toda a população, independentemente de faixa etária e/ou condições de vulnerabilidade ${ }^{72}$.

$\mathrm{Na}$ população geral, poucos estudos sobre a prevalência de $I O B$ são encontrados, que tem sido relatada em várias partes do mundo, inclusive em áreas de baixa endemicidade para o VHB. Estudando-se 487 indivíduos norte-americanos, foi detectada prevalência de IOB em $18,0 \%$ dos indivíduos que apresentavam evidência prévia de infecção pelo VHB e em 8,0\% de indivíduos soronegativos para esse vírus ${ }^{73}$. Um estudo realizado em população coreana saudável, com transaminases normais, que eram VHB e VHC negativos, captou $16,0 \%$ de prevalência de $1 \mathrm{IB}^{74}$.
Outro, sobre a prevalência da $\mathrm{IOB}$ em 98 amostras de tecido hepático de indivíduos italianos, sem doença hepática, detectou a presença de 16,3\% (16/98) de casos de $I O B$, sendo que $62,5 \%(10 / 16)$ desses eram anti-HBc+ e 7,3\% (6/82) eram indivíduos soronegativos para $\mathrm{VHB}^{75}$.

Os métodos sorológicos e de biologia molecular utilizados neste estudo, considerando que a amostra era de 3.991 indivíduos residentes em Juruti, determinaram prevalência de $0,4 \%$ de portadores do $\mathrm{VHB}$ com HBsAg+NHB-DNA+ e prevalência de $0,1 \%$ de indivíduos com IOB, anti-HBc total+NHB-DNA+.

No soro de 17.677 indivíduos coreanos, divididos em dois grupos - o grupo do Centro de Promoção de Saúde (grupo HPC, 4.014 soros) e o grupo de pacientes (13.663 soros) de todos os departamentos clínicos do hospital - nos quais foram testados o HBsAg, $\circ$ anti-HBc e $O$ anti-HBs, a investigação da presença de $\mathrm{IOB}$ encontrou prevalência de $8,9 \%$ do anti-HBc+ isolado significativamente mais elevada no grupo de pacientes do que no grupo do HPC. O VHB-DNA foi detectado somente em 1,7\% (4/230) dos indivíduos com anti-HBc+ isolado, que eram pacientes com condições não relacionadas à doença crônica do fígado ${ }^{76}$.

Semelhante ao estudo em Juruti, uma investigação sobre a prevalência de IOB entre 1.401 pacientes e hemodialisados crônicos, do Japão oriental, encontrou $0,6 \% \mathrm{HBsAg}+$, com VHB-DNA+, entre os 212 pacientes $\mathrm{HBsAg}$ - com anti-HBc+; três amostras foram positivas para VHB-DNA, concluindo-se que a prevalência de IOB na amostra japonesa era de $0,3 \%{ }^{77}$. Outro estudo sobre a prevalência de IOB entre 1.451 indivíduos australianos portadores de doença hepática encontrou 0,7\% de pacientes que atendiam aos critérios de $1 \mathrm{IOB}^{78}$.

A prevalência de $I O B$ entre pessoas com história familiar de hepatite crônica pelo VHB não está bem esclarecida. Ao examinarem 747 soros de indivíduos chineses $\mathrm{HBsAg}-$, com história familiar de infecção crônica pelo VHB, e 579 doadores de sangue voluntários com $\mathrm{HBsAg}-$, Zhang et al..$^{79}$ encontraram prevalência de IOB de 8,0\% nos indivíduos com uma história familiar de infecção crônica pelo $\mathrm{VHB}$ e de $2,6 \%$ entre os doadores de sangue.

Os vários aspectos da $I O B$ ainda são incompreendidos, inclusive a própria definição e a padronização laboratorial. Apesar do desenvolvimento, em todo o mundo, de vários estudos com o objetivo de definir a prevalência e os fatores que podem contribuir para o surgimento da IOB, como área geográfica, testes laboratoriais utilizados e população investigada, ainda não se estabeleceu completamente 0 seu significado como entidade clínica.

Há que se definir o impacto da IOB na conjuntura clínica e na progressão para cirrose e $C H C$, se a $I O B$ pode ser reativada sob imunossupressão ou se pode ser transmitida por meio de transfusões de sangue e transplantes de órgãos. Com relação à saúde pública, sua importância clínica está ligada ao risco de transmissão do VHB, sendo importante determinar os grupos de risco para a IOB, visando prevenir a transmissão ${ }^{68}$. 
Deve ser dada a devida importância ao marcador sorológico de infecção prévia ou atual pelo VHB, o anti-HBc, o qual deve ser utilizado na triagem de doadores de sangue e de órgãos, em pacientes submetidos à quimioterapia ou em tratamento com imunossupressores, em indivíduos submetidos à hemodiálise e portadores de infecção por VHC, VHD e HIV, cujo resultado positivo isolado deverá ser acompanhado da pesquisa do VHB-DNA, para se confirmar ou excluir a presença de IOB.

\section{CONCLUSÃO}

A prevalência dos marcadores sorológicos da hepatite B encontrada na população examinada caracterizou o município de Juruti como de baixa endemicidade para o VHB.
Os achados deste estudo indicaram a presença de portadores de IOB em $0,1 \%$ da população de Juruti. A baixa prevalência de $I O B$ encontrada provavelmente está relacionada à baixa endemicidade do $\mathrm{VHB}$ nessa população. Em nenhum dos indivíduos com IOB foi encontrada coinfecção com VHC, VHD e HIV.

Estudos adicionais deverão ser realizados, envolvendo um maior número de amostras em outras localidades, para avaliar qual o papel da IOB na evolução da doença hepática; sua importância entre doadores de sangue e órgãos, imunossuprimidos, hemodialisados e doentes renais; e sua participação nas coinfecções com VHC, VHD e HIV, assim como a respectiva necessidade de desenvolvimento e incorporação nos protocolos de pesquisa e tratamento de novas tecnologias para a sua detecção.

\section{REFERÊNCIAS}

1 Mendes TF. Um século de vírus B. Mod Hepatol. 1984;9(1):1-6.

2 International Committee on Taxonomy of Viruses. Virus Taxonomy: 2015 Release [Internet]. London: ICTV; 2015 [cited 2016 Nov 18]. Available from: https://talk.ictvonline.org/taxonomy/p/taxonomy releases.

3 Hoofnagle JH, Seeff LB, Bales ZB, Zimmerman HJ. Type B hepatitis after transfusion with blood containing antibody to hepatitis B core antigen. N Engl J Med. 1978 Jun;298(25):1379-83.

4 Cacciola I, Pollicino T, Squadrito G, Cerenzia G, Orlando ME, Raimondo G. Occult hepatitis B virus infection in patients with chronic hepatitis $C$ liver disease. N Engl J Med. 1999 Jul;341(1):22-6.

5 Noborg U, Gusdal A, Horal P, Lindh M. Levels of viraemia in subjects with serological markers of past or chronic hepatitis B virus infection. Scand J Infect Dis. 2000;32(3):249-52

6 Raimondo G, Allain JP, Brunetto MR, Buendia MA, Chen DS, Colombo $M$, et al. Statements from the Taormina expert meeting on occult hepatitis $B$ virus infection. J Hepatol. 2008 Oct;49(4):652-7.

7 Raimondo G, Pollicino T, Squadrito G. Clinical virology of hepatitis $B$ virus infection. J Hepatol. 2003;39 Suppl 1:S26-30.

8 Lok ASF. Occult hepatitis B virus infection: diagnosis, implications and management? J Gastroenterol Hepatol. 2004 Dec;19(7):S1 14-7.

9 Chen CJ. Time-dependent events in natural history of occult hepatitis B virus infection: the importance of population-based long-term follow-up study with repeated measurements. J Hepatol. 2005 Apr;42(4):438-40.
10 Chemin I, Trépo C. Clinical impact of occult HBV infections. J Clin Virol. 2005 Dec;34 Suppl 1: S15-21.

11 Fabris P, Brown D, Tositti G, Bozzola L, Giordani MT, Bevilacqua $P$, et al. Occult hepatitis $B$ virus infection does not affect liver histology or response to therapy with interferon alpha and ribavirin in intravenous drug users with chronic hepatitis C. J Clin Virol. 2004 Mar;29(3):160-6.

12 Chazouillères O, Mamish D, Kim M, Carey K, Wright TL, Ferrell L, et al. "Occult" hepatitis B virus as source of infection in liver transplant recipients. Lancet. 1994 Jan;343(8890):142-6.

13 Dickson RC, Everhart JE, Lake JR, Wei Y, Seaberg EC, Wiesner RH, et al. Transmission of hepatitis B by transplantation of livers from donors positive for antibody to hepatitis B core antigen. Gastroenterology. 1997 Nov;113(5): 1668-74.

14 Uemoto S, Sugiyama K, Marusawa H, Inomata $\mathrm{Y}$, Asonuma K, Egawa $\mathrm{H}$, et al. Transmission of hepatitis $B$ virus from hepatitis $B$ core antibodypositive donors in living related liver transplants. Transplantation. 1998 Feb;65(4):494-9.

15 Nunes J, Marinho RT, Fonseca JE, Silva JAP, Velosa J. Prophylaxis of hepatitis $B$ reactivation with immunosuppressive therapy in rheumatic diseases. Orientations for clinical practice. Acta Reumatol Port. 2011 Apr-Jun;36(2): 110-8.

16 Mutimer D, Shaw J, Neuberger J, Skidmore S, Martin B, Hubscher $S$, et al. Failure to incriminate hepatitis $B$, hepatitis $C$, and hepatitis $E$ viruses in the aetiology of fulminant non-A non-B hepatitis. Gut. 1995 Mar;36(3):433-6. 
17 Mason A, Sallie R, Perrilo R, Rayner A, Xu L, Dohner $D E$, et al. Prevalence of herpesviridae and hepatitis $B$ virus DNA in the liver of patients with non- $A$, non-B fulminant hepatic failure. Hepatology. 1996 Dec;24(6): 1361-5.

18 Teo EK, Ostapowicz G, Hussain M, Lee WM, Fontana RJ, Lok ASF. Hepatitis $B$ infection in patients with acute liver failure in the United State. Hepatology. 2001 Apr;33(4):972-6.

19 Tamori A, Nishiguchi S, Kubo S, Enomoto M, Koh $N$, Takeda $T$, et al. Sequencing of human-viral DNA junctions in hepatocellular carcinoma from patients with HCV and occult HBV infection. J Med Virol. 2003 Apr;69(4):475-8.

20 Shibata Y, Kanata K, Tsuruta S, Hamasaki K, Hayashida $Y$, Kato $Y$, et al. Detection of hepatitis $B$ virus $X$-region DNA in liver tissue from patients with hepatitis C virus-associated cirrhosis who subsequently developed hepatocellular carcinoma. Int J Oncol. 1999 Jun; 14(6):1 153-6.

21 Kannangai R, Molmenti E, Arrazola L, Klein A, Choti M, Thomas DL, et al. Occult hepatitis B viral DNA in liver carcinomas from a region with a low prevalence of chronic hepatitis B infection. J Viral Hepat. 2004 Jul;1 1 (4):297-301.

22 Chen L, Zhao H, Yang X, Gao JY, Cheng J. HBsAgnegative hepatitis $B$ virus infection and hepatocellular carcinoma. Discov Med. 2014 Oct;18(99): 189-93.

23 Selim HS, Abou-Donia HA, Taha HA, El Azab GI, Bakry AF. Role of occult hepatitis B virus in chronic hepatitis $C$ patients with flare of liver enzymes. Eur J Intern Med. 2011 Apr;22(2):187-90.

24 Delfino CM, Eirin ME, Berini C, Malan R, Gentile E, Castillo $A$, et al. HDAg-L variants in covert hepatitis $D$ and HBV occult infection among Amerindians of Argentina: new insights. J Clin Virol. 2012 Jul;54(3):223-8.

25 Thio CL, Seaberg EC, Skolasky Jr R, Phair J, Visscher $B$, Muñoz $A$, et al. HIV-1, hepatitis $B$ virus, and risk of liver-related mortality in the Multicenter Cohort Study (MACS). Lancet. 2002 Dec;360(9349): 1921-6.

26 Pourkarim MR, Lemey P, Amini-Bavil-Olyaee S, Houspie L, Verbeeck J, Rahman M, et al. Molecular characterization of hepatitis $B$ virus strains circulating in Belgian patients co-infected with HIV and HBV: overt and occult infection. J Med Virol. 2011 Nov;83(1 1):1876-84.

27 Aghakhani A, Banifazl M, Kalantar E, Eslamifar A, Ahmadi F, Razeghi E, et al. Occult hepatitis B virus infection in hemodialysis patients with isolated hepatitis B core antibody: a multicenter study. Ther Apher Dial. 2010 Jun; 14(3):349-53.

28 Motta JS, Mello FC, Lago BV, Perez RM, Gomes SA, Figueiredo FF. Occult hepatitis B virus infection and lamivudine-resistant mutations in isolates from renal patients undergoing hemodialysis. J Gastroenterol Hepatol. 2010 Jan;25(1):101-6.
29 Said ZNA. An overview of occult hepatitis B virus infection. World J Gastroenterol. 2011 Apr; 17(15):1927-38.

30 Sav T, Gursoy S, Torun E, Sav NM, Unal A, Oymak $\mathrm{O}$, et al. Occult HBV infection in continuous ambulatory peritoneal dialysis and hemodialysis patients. Ren Fail. 2010 Jan;32(1):74-7.

31 Peres AA, Dias EA, Chesky M, Alvares-da-Silva MR, Jobim LF, Gonçalves LF, et al. Occult hepatitis B in renal transplant patients. Transpl Infect Dis. 2005 Jun;7(2):51-6.

32 Bae E, Park CH, Ki CS, Kim SJ, Huh W, Oh HY, et al. Prevalence and clinical significance of occult hepatitis B virus infection among renal transplant recipients in Korea. Scand J Infect Dis. 2012 Oct;44(10):788-92.

33 Albuquerque ACC, Coelho MRCD, Lemos MF, Moreira RC. Occult hepatitis $B$ virus infection in hemodialysis patients in Recife, State of Pernambuco, Brazil. Rev Soc Bras Med Trop. 2012 Sep-Oct;45(5):558-62.

34 Franz C, Perez RM, Zalis MG, Zalona ACJ, Rocha PTMCA, Gonçalves RT, et al. Prevalence of occult hepatitis $B$ virus infection in kidney transplant recipients. Mem Inst Oswaldo Cruz. 2013 Aug;108(5):657-60.

35 Rios-Ocampo WA, Cortes-Mancera F, Olarte JC, Soto A, Navas MC. Occult hepatitis B virus infection among blood donors in Colombia. Virol J. 2014;11:206.

36 Oluyinka $O O$, Van Tong $H$, Tien SB, Fagbami AH, Adekanle $\mathrm{O}$, Ojurongbe $\mathrm{O}$, et al. Occult hepatitis $B$ virus infection in Nigerian blood donors and hepatitis B virus transmission risks. PLoS One. 2015 Jul; 10(7):e0131912.

37 Ferreira RC. Infecção pelo vírus da hepatite B em usuários de drogas ilícitas na Região Centro-Oeste do Brasil: aspectos epidemiológicos e moleculares [tese]. Goiânia (GO): Universidade do Estado de Goiás, Instituto de Patologia Tropical e Saúde Pública; 2008. 96 p.

38 Instituto Brasileiro de Geografia e Estatística. Censo demográfico 2010 [Internet]. Rio de Janeiro: IBGE; 2010 [citado 2016 nov 18]. Disponível em: http:// www.ibge.gov.br/home/estatistica/populacao/ censo2010/calendario.shtm.

39 Nunes HM, Soares MCP, Brito EMF, Alves MM, Souza OSC, Borges AM, et al. Prevalência de infecção pelos vírus das hepatites $A, B, C$ e $D$ na demanda de um hospital no Município de Juruti, oeste do Estado do Pará, Brasil. Rev Pan-Amaz Saude. 2010 jun; 1 (2):105-11.

40 Sitnik R, Pinho JRR, Bertolini DA, Bernardini AP, Silva LC, Carrilho FJ. Hepatitis $B$ virus genotypes and precore and core mutants in Brazilian patients. J Clin Microbiol. 2004 Jun;42(6):2455-60. 
41 Gomes-Gouvêa MS, Soares MCP, Bensabath G, Carvalho-Mello IMVG, Brito EMF, Souza OSC, et al. Hepatitis $B$ virus and hepatitis delta virus genotypes in outbreaks of fulminant hepatitis (Labrea black fever) in the wester Brazilian Amazon region. J Gen Virol. 2009 Nov;90(Pt 11 ):2638-43.

42 Saitou N, Nei M. The neighbor-joining method: a new method for reconstructing phylogenetic trees. Mol Biol Evol. 1987 Jul;4(4):406-25.

43 Morice Y, Roulot D, Grando V, Stirnemann J, Gault $E$, Jeantils $V$, et al. Phylogenetic analyses confirm the high prevalence of hepatitis $\mathrm{C}$ virus (HCV) type 4 in the Seine-Saint-Denis district (France) and indicate seven different HCV-4 subtypes linked to two different epidemiological patterns. J Gen Virol. 2001 May;82(P+ 5):1001-12.

44 Sandres-Sauné K, Deny P, Pasquier C, Thibaut V, Duverlie G, lzopet J. Determining hepatitis C genotype by analyzing the sequence of the NS5b region. J Virol Methods. 2003 May;109(2):187-93.

45 Ayres M, Ayres Jr M, Ayres DL, Santos AS. BioEstat 5.0: aplicações estatísticas nas áreas das ciências biológicas e médicas. Belém: Sociedade Civil Mamirauá; 2007. 364 p.

46 Brasil. Ministério da Saúde. Consenho Nacional de Saúde. Comissão Nacional de Ética em Pesquisa. Resolução CNS n 466, de 12 de dezembro de 2012. Aprova diretrizes e normas regulamentadoras de pesquisas envolvendo seres humanos. Diário Oficial da União, Brasília (DF), 2013 jun 13. Seção $1: 59$.

47 Pereira LMMB, Martelli CMT, Merchán-Hamann E, Montarroyos UR, Braga MC, Lima MLC, et al. Population-based multicentric survey of hepatitis $B$ infection and risk factor differences among three regions in Brazil. Am J Trop Med Hyg. 2009 Aug;81 (2):240-7.

48 Sunbul M. Hepatitis B virus genotypes: global distribution and clinical importance. World J Gastroenterol. 2014 May;20(18):5427-34.

49 Carrilho FJ, Moraes CR, Pinho JRR, Mello IMVGC, Bertolini DA, Lemos MF, et al. Hepatitis B virus infection in haemodialysis centres from Santa Catarina State, Southern Brazil. Predictive risk factors for infection and molecular epidemiology. BMC Public Health. 2004 Apr;4:13.

50 Becker CE, Mattos AA, Bogo MR, Branco F, Sitnik $R$, Kretzmann NA. Genotyping of hepatitis B virus in a cohort of patients evaluated in a hospital of Porto Alegre, south of Brazil. Arq Gastroenterol. 2010 Jan-Mar;47(1):13-7.

51 Bertolini DA, Gomes-Gouvêa MS, Carvalho-Mello IMVG, Saraceni CP, Sitnik R, Grazziotin FG, et al. Hepatitis B virus genotypes from European origin explains the high endemicity found in some areas from southern Brazil. Infect Genet Evol. 2012 Aug;12(6):1295-304.
52 Nabuco LC, Mello FCA, Gomes SA, Perez RM, Soares JAS, Coelho HSM, et al. Hepatitis B virus genotypes in Southeast Brazil and its relationship with histological features. Mem Inst Oswaldo Cruz. 2012 Sep; 107(6):785-9.

53 Moura IF, Lopes EP, Alvarado-Mora MV, Pinho JR, Carrilho FJ. Phylogenetic analysis and subgenotypic distribution of the hepatitis B virus in Recife, Brazil. Infect Genet Evol. 2013 Mar; 14:195-9.

54 Conde SRSS, Móia LJP, Barbosa MSB, Amaral ISA, Miranda ECBM, Soares MCP, et al. Prevalência de genótipos e de mutantes pré-core A-1896 do vírus da hepatite $B$ e suas implicações na hepatite crônica, em uma população da Amazônia oriental. Rev Soc Bras Med Trop. 2004;37 supl 2:33-9.

55 Conde SRSS, Pinheiro LM, Lemos JAR, Demachki S, Araújo MT, Soares MCP, et al. Prevalence of genotypes and sub-genotypes of the hepatitis $B$ virus in a population of the Brazilian Amazon Region (Pará State). J Antivir Antiretrovir. 2003 Sep;5(5):108-12.

56 Viana S, Paraná R, Moreira RC, Compri AP, Macedo V. High prevalence of hepatitis $B$ virus and hepatitis $D$ virus in the Western Brazilian Amazon. Am J Trop Med Hyg. 2005 Oct;73(4):808-14.

57 Dias ALB, Oliveira CMC, Castilho MC, Silva MSP, Braga WSM. Molecular characterization of the hepatitis $B$ virus in autochthonous and endogenous populations in the Western Brazilian Amazon. Rev Soc Bras Med Trop. 2012 Jan-Feb;45(1):9-12.

58 Souto FJD, Fontes CJF, Gaspar AMC. Prevalence of hepatitis $B$ and $C$ virus markers among malariaexposed gold miners in Brazilian Amazon. Mem Inst Oswaldo Cruz. 2001 Aug;96(6):751-5.

59 Silva CO, Azevedo MSP, Soares CMA, Martins RMB, Ramos $\mathrm{CH}$, Daher RR, et al. Seroprevalence of hepatitis $B$ virus infection in individuals with clinical evidence of hepatitis in Goiânia, Goiás. Detection of viral DNA and determination of subtypes. Rev Inst Med Trop S Paulo. 2002 Nov-Dec;44(6):331-4.

60 Weber B. Genetic variability of the S gene of hepatitis B virus: clinical and diagnostic impact. J Clin Virol. 2005 Feb;32(2):102-12.

61 Kao JH, Chen PJ, Lai MY, Chen DS. Occult hepatitis $B$ virus infection and clinical outcomes of patients with chronic hepatitis C. J Clin Microbiol. 2002 Nov;40(1 1):4068-71.

62 Kramvis A, Kew M, François G. Hepatitis B virus genotypes. Vaccine. 2005 Mar;23(19):2409-23.

63 Barbosa TC. Resistência ao adefovir, entecavir e telbivudina no tratamento da hepatite B crônica [monografia]. Salvador (BA): Universidade Federal da Bahia, Faculdade de Medicina da Bahia; 2013. $38 \mathrm{p}$. 
64 Lee YS, Suh DJ, Lim YS, Jung SW, Kim KM, Lee $\mathrm{HC}$, et al. Increased risk of adefovir resistance in patients with lamivudine-resistant chronic hepatitis B after 48 weeks of adefovir dipivoxil monotherapy. Hepatology. 2006 Jun;43(6):1385-91.

65 Yokosuka O, Takaguchi K, Fujioka S, Shindo M, Chayama K, Kobashi $\mathrm{H}$, et al. Long-term use of entecavir in nucleoside-naïve Japanese patients with chronic hepatitis B infection. J Hepatol. 2010 Jun;52(6):791-9.

$66 \mathrm{Kao} J H$, Chen PJ, Lai MY, Chen DS. Hepatitis B genotypes correlate with clinical outcomes in patients with chronic hepatitis B. Gastroenterology. 2000 Mar; 1 18(3):554-9.

67 Neau D, Winnock, M, Jouvencel AC, Faure $M$, Castéra $L$, Legrand $E$, et al. Occult hepatitis $B$ virus infection in HIV-infected patients with isolated antibodies to hepatitis B core antigen: aquitaine cohort, 2002-2003. Clin Infect Dis. 2005 Mar;40(5):750-3.

68 Barros Júnior GM, Braga WSM, Oliveira CMC, Castilho MC, Araújo JR. Hepatite crônica B oculta: prevalência e aspectos clínicos em população de elevada endemicidade de infecção pelo vírus da hepatite B na Amazônia ocidental brasileira. Rev Soc Bras Med Trop. 2008 jan-dez;41 (6):596-601.

69 Ocana S, Casas ML, Buhigas I, Lledo JL. Diagnostic strategy for occult hepatitis B virus infection. World J Gastroenterol. 2011 Mar; 17(12):1553-7.

70 Escobedo-Melendez G, Panduro A, Fierro NA, Roman S. High prevalence of occult hepatitis $B$ virus genotype $\mathrm{H}$ infection among children with clinical hepatitis in west Mexico. Mem Inst Oswaldo Cruz. 2014 Sep;109(6):728-37.

71 Ministério da Saúde (BR). Departamento de Informática do Sistema Único de Saúde. Cobertura vacinal contra hepatite $B$, por faixa etária, na série histórica de terceiras doses aplicadas, Estados, Região e Brasil, 1994 a 2011 [Internet]. Brasília: Ministério da Saúde; 2012 [citado 2016 jan 26]. Disponível em: http://pni.datasus.gov.br/download sh Hepatite B 2011.asp.
72 Brasil. Ministério da Saúde. Secretaria de Vigilância em Saúde. Departamento de Vigilância das Doenças Transmissíveis. Coordenação Geral do Programa Nacional de Imunizações. Nota Informativa $\mathrm{n}^{\circ}$ 149/CGPNI/DEVIT/SVS/MS, 2015. Informa as mudanças no Calendário Nacional de Vacinação para o ano de 2016. Brasília: DEVIT; 2015

73 Minuk GY, Sun DF, Uhanova J, Zhang M, Caouette $S$, Nicolle LE, et al. Occult hepatitis $B$ virus infection in a North American community-based population. J Hepatol. 2005 Apr;42(4):480-5.

74 Kim SM, Lee KS, Park CJ, Lee JY, Kim KH, Park JY, et al. Prevalence of occult HBV infection among subjects with normal serum ALT levels in Korea. J Infect. 2007 Feb;54(2):185-91.

75 Raimondo G, Navarra G, Mondello S, Costantino L, Colloredo G, Cucinotta E, et al. Occult hepatitis $B$ virus in liver tissue of individuals without hepatic disease. J Hepatol. 2008 May;48(5):743-6.

76 Kang SY, Kim MH, Lee WI. The prevalence of "anti-HBc alone" and HBV DNA detection among anti-HBc alone in Korea. J Med Virol. 2010 Sep;82(9):1508-14

77 Nagakawa $O$, Miyatomi $Y$, Shigeta $Y$, Inayama E, Murakami K, Sakai T, et al. Occult hepatitis B virus infection in Japanese chronic hemodialysis patients. Ther Apher Dial. 2013 Jun;17(3):289-92.

78 Martinez MC, Kok CC, Baleriola C, Robertson P, Rawlinson WD. Investigation of occult hepatitis $B$ virus infection in anti-HBc positive patients from a liver clinic. PLoS One. 2015 Mar;10(3): e0117275.

79 Zhang Z, Zhang L, Dai Y, Jin L, Sun B, Su Q, et al. Occult hepatitis $B$ virus infection among people with a family history of chronic hepatitis $B$ virus infection. J Med Virol. 2015 Nov;87(11): 1890-8. 